Article

\title{
Effects of an Alternating Magnetic Field/Ag Multi-Alloying Combined Solidification Process on $\mathrm{Cu}-14 \mathrm{Fe}$ Alloy
}

\author{
Jin Zou ${ }^{1, *}$, De-Ping Lu ${ }^{1, *}$, Ke-Ming Liu ${ }^{2}$ and Qing-Feng Fu ${ }^{1}$ \\ 1 Jiangxi Key Laboratory for Advanced Copper and Tungsten Materials, Jiangxi Academy of Sciences, \\ Nanchang 330029, China; fuqingfeng@jxas.ac.cn \\ 2 Jiangxi Key Laboratory for Precision Drive and Control, Nanchang Institute of Technology, \\ Nanchang 330099, China; jokeliu@sina.com \\ * Correspondence: niatzou@126.com (J.Z.); ludeping61@163.com (D.-P.L.)
}

Received: 7 November 2018; Accepted: 6 December 2018; Published: 9 December 2018

\begin{abstract}
An alternating magnetic field (AMF)/Ag multi-alloying combined process was applied to the solidification of $\mathrm{Cu}-14 \mathrm{Fe}$ alloy to study its effects on the microstructure and properties of the resulting samples. The applied AMF and Ag multi-alloying had positive effects on the refinement of the primary Fe phase and precipitation of Fe solute atoms, respectively. These results indicated that the combined AMF/Ag multi-alloying process was effective to improve the distribution of the primary Fe phase and reduce the Fe content of the $\mathrm{Cu}$ matrix, which increased the conductivity of the alloy. The application of the combined AMF/Ag multi-alloying process to the solidification of $\mathrm{Cu}-\mathrm{Fe}$ alloy provided samples with improved comprehensive properties compared with those of samples solidified using a single process (AMF or Ag multi-alloying).
\end{abstract}

Keywords: $\mathrm{Cu}-\mathrm{Fe}$ alloy; Ag multi-alloying; combined process; solid solution

\section{Introduction}

High-strength and high-conductivity deformation-processed Cu-based in situ composites exhibit favorable physical and mechanical properties. Such composites not only have excellent electrical and thermal conductivity but also possess high strength and plasticity, which means they are attractive for applications in the fields of electronics, vehicles, metallurgy, and energy [1-3]. Recent studies have shown that $\mathrm{Fe}$ is an appropriate strengthening phase for $\mathrm{Cu}$-based composites. $\mathrm{Cu}-\mathrm{Fe}$ deformation-processed in situ composites are considered to be of great industrial application value because of their excellent mechanical properties and low production cost. However, the insufficient precipitation of Fe solute atoms in the $\mathrm{Cu}$ matrix during the solidification process greatly limits the comprehensive properties of $\mathrm{Cu}-\mathrm{Fe}$ composites [4]. It is important to determine how to inhibit Fe atom dissolution in $\mathrm{Cu}$ crystals and promote $\mathrm{Fe}$ solute atom precipitation from the $\mathrm{Cu}$ matrix to minimize the harmful effects of Fe atoms on the conductivity of the $\mathrm{Cu}$ matrix.

Researchers have introduced multi-alloying in $\mathrm{Cu}-\mathrm{Fe}$ alloys to accelerate the precipitation of $\mathrm{Fe}$ during the solidification process by addition of micro-alloy elements, thus inhibiting the dissolution of Fe atoms in the $\mathrm{Cu}$ matrix. Ag has been widely studied as a third component to lower the solid solubility of $\mathrm{Fe}$ in $\mathrm{Cu}$, and improve the strength of the material without markedly worsening the conductivity [2,5-8]. Meanwhile, because Fe atoms diffuse relatively slowly from a supersaturated $\mathrm{Cu}$ solid solution at room temperature, intermediate heat treatment and final aging treatment are often used to promote precipitation of Fe atoms [9-11]. However, these treatments cause grain coarsening and recovery, thus decreasing the strength of the resulting materials. We previously found that the application of an alternating magnetic field (AMF) during the solidification process of $\mathrm{Cu}-\mathrm{Fe}$ alloys 
markedly refined Fe grains and effectively reduced the content of Fe solute atoms in the Cu matrix, which was conducive to improve the comprehensive properties of alloys [12,13]. Based on the previous studies, here an AMF/Ag multi-alloy combined process is established. Focusing on $\mathrm{Cu}-14 \mathrm{Fe}$ alloy in this work, the influence of the combined solidification process on microstructure is examined, and the solute distribution and material properties of the obtained samples are evaluated. The aims of this work were (i) to understand the influence of $\mathrm{Ag}$ as a multi-alloy addition, (ii) to determine the significance of the AMF/Ag multi-alloy combined process on $\mathrm{Cu}-14 \mathrm{Fe}$ alloy, and (iii) to develop a new method in the research and development of $\mathrm{Cu}$-Fe deformation-processed in situ composites.

\section{Experimental}

The raw materials were electrolytic copper $(99.96 \mathrm{wt} \%)$, pure iron $(99.94 \mathrm{wt} \%)$, and pure silver (99.95 wt \%). Experimental alloys ( $\mathrm{Cu}-14 \mathrm{Fe}, \mathrm{Cu}-14 \mathrm{Fe}-0.1 \mathrm{Ag}, \mathrm{Cu}-14 \mathrm{Fe}-0.5 \mathrm{Ag}$, and $\mathrm{Cu}-14 \mathrm{Fe}-1 \mathrm{Ag}$ ) were melted in a magnesia crucible (Dashiqiao crucible factory, Yingkou, China with a medium-frequency induction furnace (Jinzhou Institute of Metallurgical Technology, Jinzhou, China) possessing a rated power of 35kw, and were then solidified in a graphite crystallizer (diameter $\Phi 112 \mathrm{~mm}$ ) installed in a magnetic field generating system. The temperature of the melt was measured in real time using an infrared thermometer (IRP20, OPTRIS, Berlin, Germany). The solidification experiment was carried out in an AMF generator (IDEA Electric CO.LTD, Shijiazhuang, China) possessing a magnetic flux density of $30 \mathrm{mT}$ and field frequency of $26 \mathrm{~Hz}$.

The ingots were initially cut longitudinally along the diameter and the smaller-sized samples were prepared by a wire-electrode cutting to $10 \times 10 \mathrm{~mm}^{2}$. The samples for investigating the microstructure were polished and etched using a solution of $\mathrm{FeCl}_{3}: \mathrm{HCl}: \mathrm{H}_{2} \mathrm{O}=1: 2: 20$ and were subsequently observed with an optical microscope (OM; DMI3000M, Leica Microsystems, Wetzlar, Germany). The Fe grain size distributions were measured from the OM images using Image-Pro Plus software (6.0, Media Cybernetics, Rockville, MD, USA). Element distribution was analyzed using a scanning electron microscope (SEM; Quanta 200, FEI, Hillsboro, OR, USA) and energy dispersion spectroscopy (EDS; Oxford, UK). The phase structure of the samples was determined via X-ray diffraction (XRD; D8-Advance, Bruker, Billerica, MA, USA) using a tube voltage of $40 \mathrm{kV}$ and a CuK $\alpha$ wavelength of $1.5418 \AA$. The microhardness was measured using a Vickers hardness tester (Model: HXS-1000, Shanghai Taiming Optical Instrument, Shanghai, China) at a load of $50 \mathrm{~g}$ and duration time of $15 \mathrm{~s}$. The conductivity was measured using an eddy conductivity meter (Model: FD-102, Xiamen First Electronic Technology, Xiamen, China).

\section{Results and Discussion}

\subsection{Microstructure}

Figure 1 presents the microstructures of $\mathrm{Cu}-14 \mathrm{Fe}$ and $\mathrm{Cu}-14 \mathrm{Fe}-0.1 \mathrm{Ag}$ alloys produced by normal solidification. Copper and iron do not form alloy phase during solidification, the typical microstructure of the $\mathrm{Cu}-14 \mathrm{Fe}$ alloys consisted of primary Fe dendrites distributed in the $\mathrm{Cu}$ matrix with random orientations. The addition of $0.1 \mathrm{wt} \% \mathrm{Ag}$ affected the growth of Fe dendrites, decreasing the average sizes of the irregularly shaped grains and secondary dendritic arms. Figure 2 depicts the microstructures of $\mathrm{Cu}-14 \mathrm{Fe}$ alloys with various $\mathrm{Ag}$ contents produced under an AMF. The application of an AMF helped to refine and disperse Fe dendrites in the $\mathrm{Cu}$ matrix. With increasing Ag content, the size of the Fe grains in the samples was further refined. 


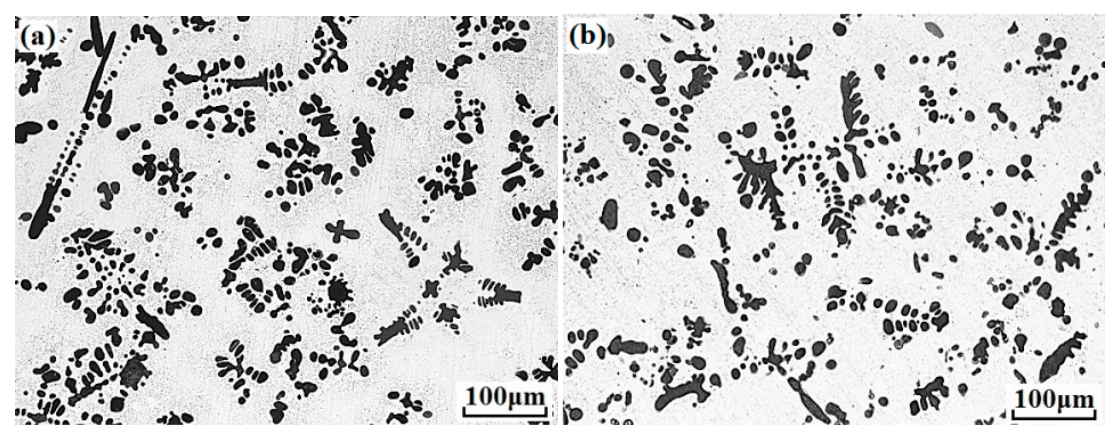

Figure 1. Microstructures of alloys with normal solidification: (a) $\mathrm{Cu}-14 \mathrm{Fe}$; (b) $\mathrm{Cu}-14 \mathrm{Fe}-0.1 \mathrm{Ag}$.

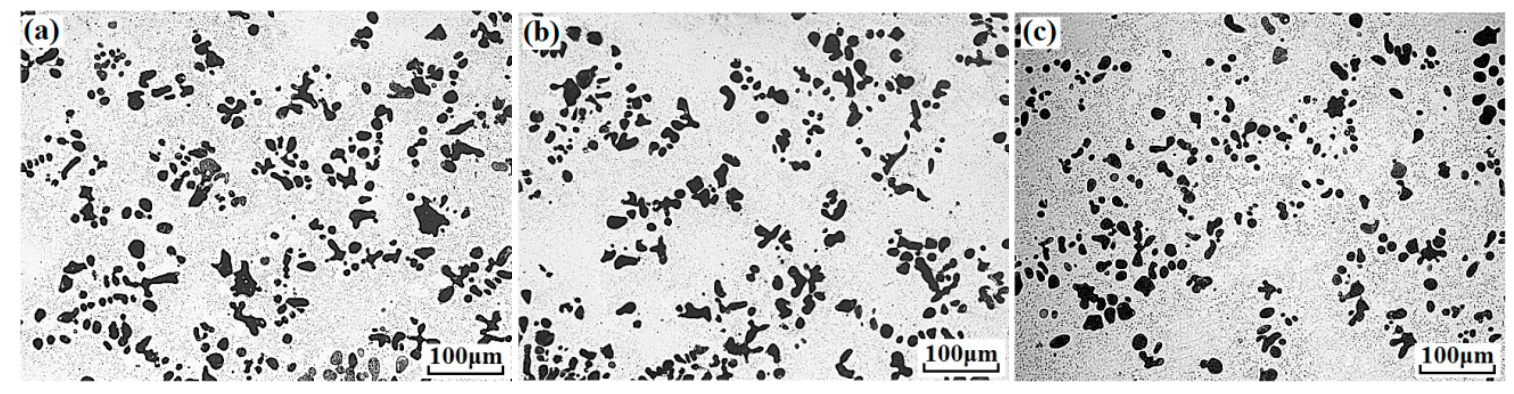

Figure 2. Microstructures of alloys solidified with alternating magnetic field (AMF): (a) $\mathrm{Cu}-14 \mathrm{Fe}-0.1 \mathrm{Ag}$;

(b) $\mathrm{Cu}-14 \mathrm{Fe}-0.5 \mathrm{Ag}$; (c) $\mathrm{Cu}-14 \mathrm{Fe}-1 \mathrm{Ag}$.

The average size and size distribution of the Fe grains in samples produced under various solidification conditions are listed in Table 1 and shown in Figure 3, respectively. As shown in Figure 3, the size distribution of the Fe grains changed markedly with the combined solidification process. Compared with that of the sample obtained by normal solidification, the proportion of grain sizes smaller than $10 \mu \mathrm{m}$ increased and the proportion of grains larger than $30 \mu \mathrm{m}$ decreased gradually. In contrast to the combined solidification process, the variation of $\mathrm{Ag}$ content in the $\mathrm{Cu}-14 \mathrm{Fe}$ alloy had only a small effect on the average size of the Fe grains.

Table 1. Average Fe grain sizes of the various solidification processes.

\begin{tabular}{cccc}
\hline Code & Alloy & Solidification Process & Average Fe Grain Size $(\mu \mathrm{m})$ \\
\hline $\mathrm{N}-0$ & $\mathrm{Cu}-14 \mathrm{Fe}$ & \multirow{2}{*}{ Normal } & 13.3 \\
$\mathrm{~N}-0.1$ & $\mathrm{Cu}-14 \mathrm{Fe}-0.1 \mathrm{Ag}$ & & 12.3 \\
\hline $\mathrm{A}-0.1$ & $\mathrm{Cu}-14 \mathrm{Fe}-0.1 \mathrm{Ag}$ & $\mathrm{AMF}$ & 9.99 \\
$\mathrm{~A}-0.5$ & $\mathrm{Cu}-14 \mathrm{Fe}-0.5 \mathrm{Ag}$ & & 9 \\
$\mathrm{~A}-1$ & $\mathrm{Cu}-14 \mathrm{Fe}-1 \mathrm{Ag}$ & & 9.36 \\
\hline
\end{tabular}

Addition of a trace amount of $\mathrm{Ag}$ to the $\mathrm{Cu}-\mathrm{Fe}$ alloy had a certain inhibition effect on the size of the Fe grains formed. Similar results have been found in the study of $\mathrm{Cu}-\mathrm{Nb}$ alloy [14] and $\mathrm{Cu}-\mathrm{Cr}$ alloy [15]. The size of the primary-phase dendrites in the as-cast $\mathrm{Cu}$ base alloy is obviously refined through the action of Ag. Gao et al. [16] reported that Ag can behave as a modifier that can promote nucleation, refining and spheroidizing of the Fe dendrites during the solidification process. In this study, we found that a trace amount of Ag refined the size of the Fe grains but did not obviously make the Fe grains become spherical.

The application of an AMF in the solidification process helped to promote the Fe nucleation and decrease the size of the Fe grains. However, increasing the Ag content had no obvious effect on grain size refinement in the combined process. This may be because the application of an AMF already strongly promotes the refinement of the Fe grains, and the refinement of Fe grains is not a superposition of the effect of the AMF and that of Ag; therefore, the effect of Ag multi-alloying on grain refinement has been covered in the combined process. 


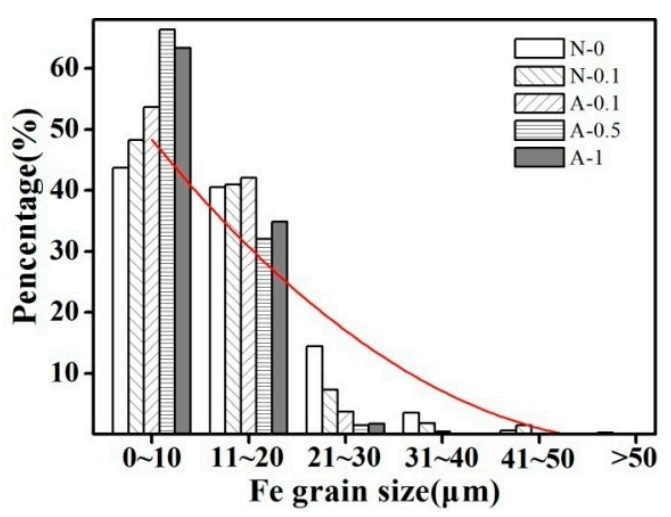

Figure 3. Fe grain size distributions of the various solidification processes.

\subsection{Solution Distribution}

Figure 4 presents the Fe content of the $\mathrm{Cu}$ matrix for samples produced with the addition of $\mathrm{Ag}$ in the combined process. The Fe content of the $\mathrm{Cu}$ matrix includes the Fe atoms dissolved in the $\mathrm{Cu}$ grains and the secondary Fe particles precipitated from the $\mathrm{Cu}$ grains during the solidification process, which can reflect the solid solubility of $\mathrm{Fe}$ in $\mathrm{Cu}$ at the solidus. As shown in Figure 4, the addition of $\mathrm{Ag}$ helps to reduce the Fe content of the $\mathrm{Cu}$ matrix. With increasing Ag content, the Fe content of the $\mathrm{Cu}$ matrix decreases, and the change gradually lessens with increasing Ag content. Wang et al. [17] presented a first-principles calculation that indicated that Ag atoms are more soluble than Fe atoms in $\mathrm{Cu}$. Thus, $\mathrm{Ag}$ atoms can occupy $\mathrm{Cu}$ lattice positions before Fe atoms, which inhibit Fe atoms from dissolving in $\mathrm{Cu}$, lowering the solid solubility of $\mathrm{Fe}$ in $\mathrm{Cu}$.

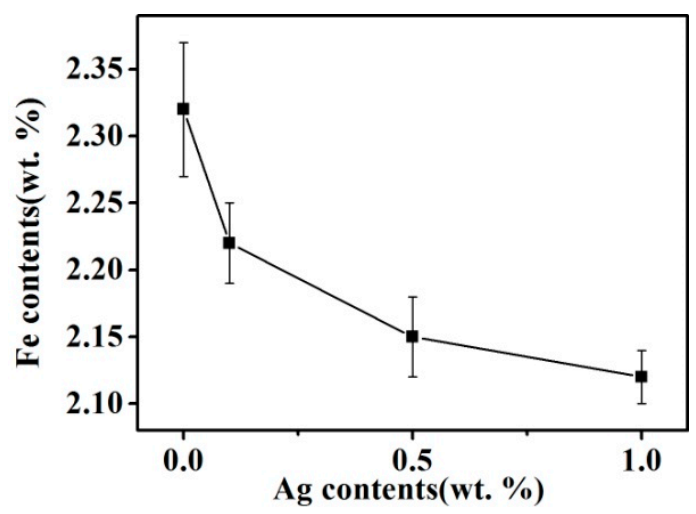

Figure 4. Fe content in $\mathrm{Cu}$ matrix of alloys solidified with the combined process.

Fe and Ag have different crystal structures at room temperature (body-centered cubic and face-centered cubic, respectively), and the difference between their atomic radii is $16.9 \%$, which does not meet the requirement for anatomic radius difference of less than $15 \%$ in substitutional solid solutions. Therefore, $\mathrm{Ag}$ and Fe are almost insoluble in each other, and Ag is completely in solid solution in a Cu matrix.

Figure 5 presents the XRD patterns of the $\mathrm{Cu}-14 \mathrm{Fe}$ alloys obtained by the combined process. Because the Ag atoms are almost in a solid solution in the $\mathrm{Cu}$ crystal, no characteristic Ag peaks were observed. However, the characteristic $\mathrm{Cu}$ peaks were broadened and shifted as a result of the formation of a solid solution with $\mathrm{Ag}$. Figure $5 \mathrm{~b}$ shows the position of the $\mathrm{Cu}(111)$ diffraction peak for the samples. Compared with that for $\mathrm{Cu}-14 \mathrm{Fe}$ alloy, the diffraction peak shifted to a lower angle upon the addition of Ag. The peak shift increased with the content of Ag, which was caused by the change in the lattice constant of the sample. The XRD behavior of a crystal follows Bragg's law:

$$
2 d \sin \theta=n \lambda
$$


where $d$ is the lattice constant, $\theta$ is the incident angle, $\lambda$ is the wavelength of the X-ray beam, and $n$ is the diffraction series. Thus, the decrease of $\theta$ indicates the increase of $d$. The atomic radius of Ag is larger than that of $\mathrm{Cu}$, so the $\mathrm{Ag}$ solid solution in the $\mathrm{Cu}$ crystal will increase both the lattice constant of the $\mathrm{Cu}$ crystal and the lattice distortion. The higher the content of Ag atoms, the larger the lattice constant of the $\mathrm{Cu}$ crystals, and the smaller the $\theta$. Therefore, the shift of the $\mathrm{Cu}$ diffraction peak to a lower angle indicates the increasing Ag content of the $\mathrm{Cu}$ matrix.

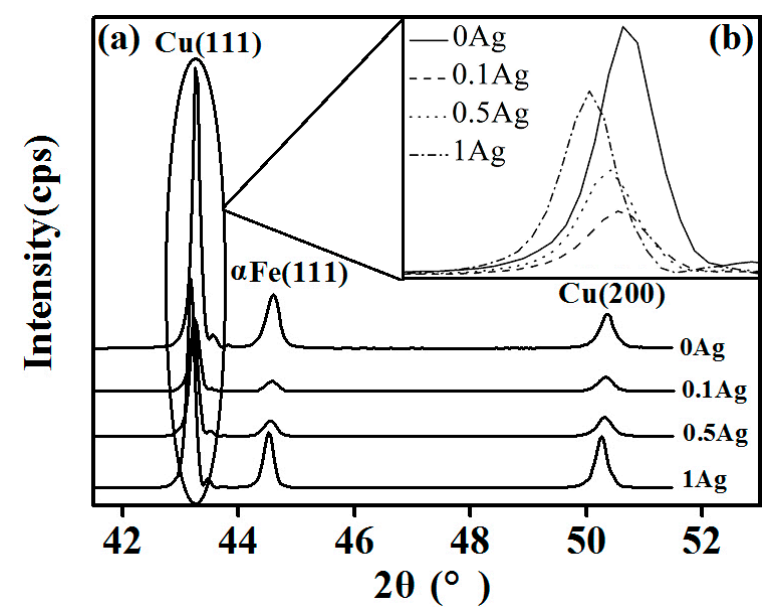

Figure 5. XRD spectra: (a) $\mathrm{Cu}-\mathrm{Fe}-\mathrm{xAg}$ alloy $(\mathrm{x}=0,0.1,0.5,1)$; (b) $\mathrm{Cu}(111)$ diffraction peak.

\subsection{Microhardness}

Figure 6 presents the hardness of the $\mathrm{Cu}-14 \mathrm{Fe}$ alloys produced by the combined process. With increasing Ag content, the average hardness of the samples rose slightly. However, considering the measured standard deviation, the effect of Ag content on the hardness of the samples was not obvious.

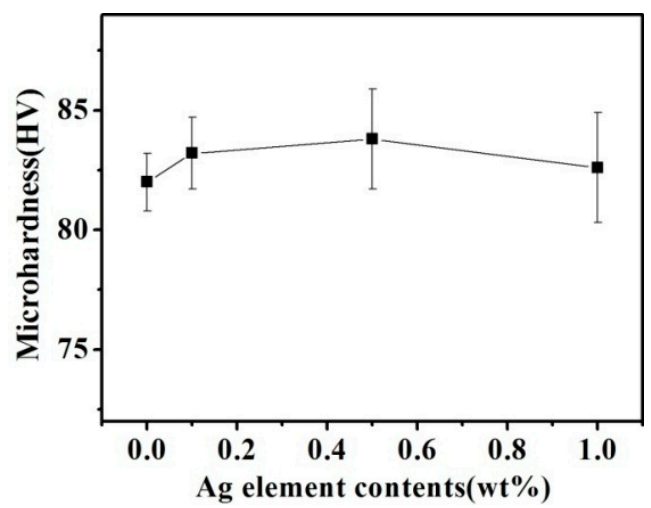

Figure 6. Cu matrix hardness of $\mathrm{Cu}-14 \mathrm{Fe}$ alloys solidified with the combined process.

According to the strengthening mechanism of the $\mathrm{Cu}$ matrix in $\mathrm{Cu}-\mathrm{Fe}$ alloy, the hardness of the sample depends on both solution strengthening and precipitation strengthening [18]. The solution of $\mathrm{Ag}$ atoms in the $\mathrm{Cu}$ matrix is beneficial to improve the solution strengthening effect of the $\mathrm{Cu}$ matrix, and $\mathrm{Ag}$ is completely soluble in the $\mathrm{Cu}$ matrix. Therefore, the strengthening model of the $\mathrm{Cu}$ matrix in the $\mathrm{Cu}-\mathrm{Fe}-\mathrm{Ag}$ alloy samples can be expressed as:

$$
H V_{\text {matrix }}=\left(f_{F e-\varepsilon} \cdot H V_{F e-\varepsilon}+f_{A g-\varepsilon} \cdot H V_{A g-\varepsilon}+f_{F e-p r e} \cdot H V_{F e}\right)+k f_{F e-p r e}^{1 / 2}
$$

where $f_{\mathrm{Fe}-\varepsilon}, f_{\mathrm{Ag}-\varepsilon}$, and $f_{\mathrm{Fe}-\text { pre }}$ are the volume fractions of the $\mathrm{Cu}(\mathrm{Fe})$ solid solution, $\mathrm{Cu}(\mathrm{Ag})$ solid solution, and Fe precipitation particles, respectively; and, $H V_{\mathrm{Fe}-\varepsilon}, H V_{\mathrm{Ag}-\varepsilon}$, and $H V_{\mathrm{Fe}}$ are the hardness of the $\mathrm{Cu}(\mathrm{Fe})$ solid solution, $\mathrm{Cu}(\mathrm{Ag})$ solid solution, and Fe precipitation particles, respectively. 
Because the $\mathrm{Ag}$ atoms can dissolve in the $\mathrm{Cu}$ crystal prior to $\mathrm{Fe}$ and thus inhibit the dissolution of $\mathrm{Fe}$ atoms in $\mathrm{Cu}$, the addition of $\mathrm{Ag}$ to the $\mathrm{Cu}-\mathrm{Fe}$ alloy increases $f_{\mathrm{Ag}-\varepsilon}$ and decreases $f_{\mathrm{Fe}-\varepsilon}$. The atomic radii of $\mathrm{Cu}, \mathrm{Fe}$, and $\mathrm{Ag}$ atoms are 128, 124, and $144 \mathrm{pm}$, respectively, so both $\mathrm{Cu}-\mathrm{Fe}$ and $\mathrm{Cu}-\mathrm{Ag}$ can form substitutional solid solutions. Because the difference between the radius of $\mathrm{Cu}$ and $\mathrm{Ag}$ atoms is larger than that between $\mathrm{Cu}$ and $\mathrm{Fe}$ atoms, the lattice distortion in the $\mathrm{Cu}$ crystal induced by solute $\mathrm{Ag}$ atoms is larger than that caused by solute Fe atoms. This means that the solution strengthening effect of the $\mathrm{Cu}(\mathrm{Ag})$ solid solution is greater than that of the $\mathrm{Cu}-(\mathrm{Fe})$ solid solution; i.e., the addition of $\mathrm{Ag}$ can increase the hardness of the $\mathrm{Cu}$ matrix to a greater extent than the addition of Fe.

Although the dissolution of $\mathrm{Ag}$ atoms can improve the solution strengthening of the $\mathrm{Cu}$ matrix, it also promotes the precipitation of the Fe atoms, thus lowering the solution strengthening of the $\mathrm{Fe}$ atoms. A trace amount of Ag used in our experiments had little effect on the dissolved atoms in the $\mathrm{Cu}$ matrix. Therefore, the hardness of the samples did not change obviously under the combined actions of the solid solution and precipitation.

\subsection{Conductivity}

Figure 7 presents the conductivity of the $\mathrm{Cu}-14 \mathrm{Fe}$ alloy samples produced using the $\mathrm{Ag}$ multi-alloying and combined process. Ag multi-alloying raised the conductivity of $\mathrm{Cu}-14 \mathrm{Fe}$ alloy which evaluated with \%IACS (International Annealed Copper Standard). The conductivity of the alloy was further raised when it was produced using the combined process.

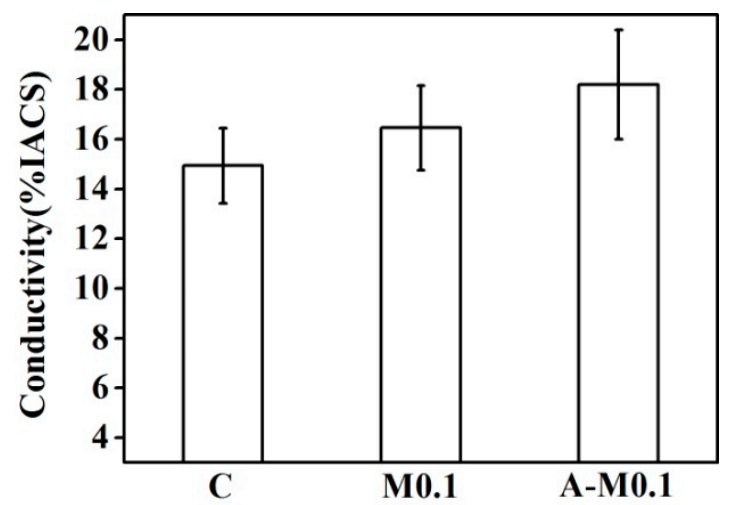

Figure 7. Conductivity of alloys solidified with the Ag multi-alloying and combined process.

Figure 8 shows the conductivity of $\mathrm{Cu}-14 \mathrm{Fe}$ alloy samples with various $\mathrm{Ag}$ contents produced by the combined process. Increasing the Ag content of the alloy markedly improved its conductivity for the samples produced by the combined process; however, the increase of conductivity weakened with increasing Ag content. The conductivity of the alloy solidified by the A-M1 (Code) process was about $33 \%$ higher than that of the sample obtained by $\mathrm{N}-0$ (Code). Impurity scattering in the Cu matrix is mainly caused by Fe atoms in the $\mathrm{Cu}$ solid solution. Although most Fe atoms precipitated gradually during the cooling process, a trace amount of Fe still remained in the $\mathrm{Cu}$ matrix as solid solution atoms. The diffusion of $\mathrm{Fe}$ atoms in the $\mathrm{Cu}$ matrix is slow and they hardly precipitate at room temperature. The resistivity of the Cu matrix increased to $9.2 \mu \Omega \cdot \mathrm{cm}$ when it contained $1 \mathrm{wt} \%$ Fe solid solution atoms, and the precipitated Fe particles have little effect on the conductivity of the Cu matrix compared with Fe atoms in the solid solution [19]. It is assumed that the decrease of Fe content in the Cu matrix is related to the dissolved $\mathrm{Fe}$ atoms in the $\mathrm{Cu}$ matrix rather than the precipitated Fe particles. Moreover, the effect of Ag atoms, impurities, and the Fe-precipitated particles on the resistivity is ignored. The influence of dissolved Fe atoms $\Delta x$ on the resistivity of the $\mathrm{Cu}$ matrix $\Delta \rho$ can be expressed as follows:

$$
\Delta \rho=\Delta x \cdot 9.2(\mu \Omega \cdot \mathrm{cm})
$$


Therefore, on the basis of the change of Fe content in the Cu matrix (Figure 4), the effect of Fe content in the $\mathrm{Cu}$ matrix on conductivity can be calculated as follows:

$$
\Phi=\frac{1.7241}{\rho-\Delta \rho} \times 100 \% \mathrm{IACS}
$$

The calculated conductivity values for samples solidified by the combined process are also plotted in Figure 8. The calculated values agree well with the measured values and their variation trends are consistent. The addition of $\mathrm{Ag}$ can inhibit dissolution of $\mathrm{Fe}$ in $\mathrm{Cu}$ and decrease the content of Fe atoms in the $\mathrm{Cu}$ matrix, which helps to lower the impurity scattering resistance of the $\mathrm{Cu}$ matrix. Because the primary Fe grains and Fe precipitated particles have little influence on the conductivity of the samples, this also verified that the change of Fe content in the Cu matrix is mainly that of the dissolved Fe atoms in the $\mathrm{Cu}$ matrix. The combined process can promote the precipitation of $\mathrm{Fe}$ atoms in the $\mathrm{Cu}$ matrix.

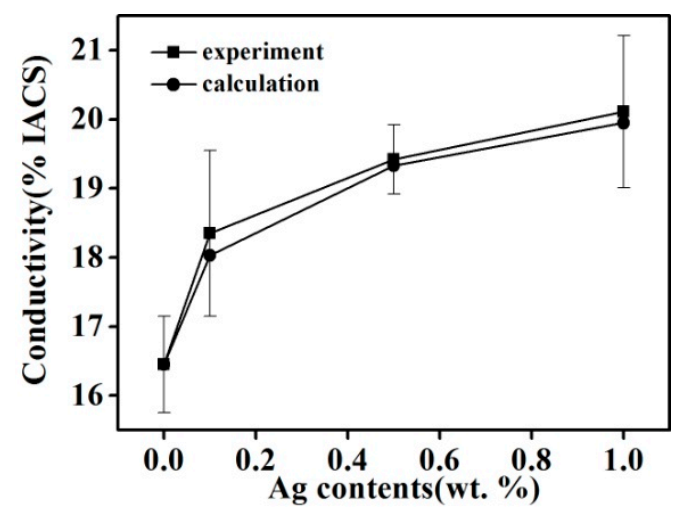

Figure 8. Experimental and calculated values of the conductivity of $\mathrm{Cu}-14 \mathrm{Fe}-\mathrm{xAg}$ alloy $(\mathrm{x}=0,0.1,0.5,1)$.

\section{Conclusions}

(1) The addition of a trace amount of $\mathrm{Ag}$ to $\mathrm{Cu}-\mathrm{Fe}$ alloy helped to refine primary Fe grains during the solidification process and promote uniform distribution of the Fe grains. The higher the Ag content, the greater the Fe grains were refined. The effect of refining and dispersing of the Fe grains was larger for samples produced by the AMF/Ag multi-alloying combined process than for those produced with AMF or Ag multi-alloying alone.

(2) The AMF/Ag multi-alloying combined process markedly decreased the Fe content of the $\mathrm{Cu}$ matrix. The Fe content of the $\mathrm{Cu}$ matrix decreased gradually with increasing Ag content and this change gradually weakened with rising Ag content.

(3) The decrease of Fe content in the $\mathrm{Cu}$ matrix caused by the combined process was mainly related to the decrease of the dissolved Fe atoms in the $\mathrm{Cu}$ matrix. The decreased content of dissolved $\mathrm{Fe}$ atoms in $\mathrm{Cu}$ helped to lower the impurity scattering resistance of the $\mathrm{Cu}$ matrix, and thus the conductivity of the alloy was improved.

Author Contributions: Data curation, J.Z.; Funding acquisition, D.-P.L. and K.-M.L.; Investigation, K.-M.L. and Q.-F.F.; Methodology, D.-P.L.; Writing original draft, J.Z.

Funding: This study was supported by the National Natural Science Foundation of China (Nos. 51861025; 51561010), Jiangxi Academy of Sciences (No. 2017-YZDZ-07), Technology Program of Jiangxi Education Department (GJJ170976), and Key Research and Development Program of Jiangxi Province (20171BBH80009).

Conflicts of Interest: The authors declare no conflict of interest.

\section{References}

1. Gan, C.L.; Liu, H.; Zheng, K.H.; Liu, Y.N.; Wang, H.Y. Manufactured process of high strength and high electrical conductivity Cu-Cr-Zr-Mg alloy bars. Mater. Sci. Forum 2017, 898, 1215-1219. [CrossRef] 
2. Shi, G.D.; Jiang, H.; Wang, Z.D.; Chen, X.H. Microstructure and Properties of Cu-Fe-Co Alloy Obtained by Directional Solidification. In Proceedings of the 2015 International Conference on Electronics, Electrical Engineering and Information Science; World Scientific: Singapore, 2016; pp. 957-965.

3. Rdzawski, Z.; Gluchowski, W.; Stobrawa, J.; Kempinski, W.; Andrzejewski, B. Microstructure and properties of nanofilament $\mathrm{Cu}-\mathrm{Nb}$ and $\mathrm{Cu}-\mathrm{Ag}$ composites. Physics 2014, 74, 689-697.

4. Xie, Z.; Gao, H.Y.; Dong, S.J.; Wang, J.; Huang, H.; Luo, P. Enhanced strength and electrical conductivity of $\mathrm{Cu}-8 \mathrm{Fe}$ composite by adding trace Ag and P. Mater. Trans. 2013, 54, 2075-2078. [CrossRef]

5. Liu, K.; Huang, Z.; Zhang, X.; Lu, D.; Atrens, A.; Zhou, H.; Yin, Y.; Yu, J.; Guo, W. Influence of Ag micro-alloying on the thermal stability and ageing characteristics of a $\mathrm{Cu}-14 \mathrm{Fe}$ in-situ composite. Mater. Sci. Eng. A 2016, 673, 1-7. [CrossRef]

6. Bao, G.H.; Chen, Y.; Ma, J.E.; Fang, Y.T.; Meng, L.; Zhao, S.M.; Wang, X.; Liu, J.B. Microstructure and properties of cold drawing $\mathrm{Cu}-2.5 \% \mathrm{Fe}-0.2 \% \mathrm{Cr}$ and $\mathrm{Cu}-6 \% \mathrm{Fe}$ alloys. J. Zhejiang Univ. A 2015, 16, 622-629. [CrossRef]

7. Slimi, M.; Azabou, M.; Escoda, L.; Suñol, J.J.; Khitouni, M. Structural and microstructural properties of nanocrystalline $\mathrm{Cu}-\mathrm{Fe}-\mathrm{Ni}$ powders produced by mechanical alloying. Powder Technol. 2014, 266, 262-267. [CrossRef]

8. Jo, H.R.; Kim, J.T.; Hong, S.H.; Kim, Y.S.; Park, H.J.; Park, W.J.; Jin, M.P.; Kim, K.B. Effect of silicon on microstructure and mechanical properties of Cu-Fe alloys. J. Alloy. Compd. 2016, 707, 184-188. [CrossRef]

9. Zhou, J.B.; Wang, E.G.; Zuo, X.W.; Qu, L.; Zhang, L.; He, J.C. Thermo-mechanical processing and properties of $\mathrm{Cu}-12.8 \%$ Fe composites. Trans. Mater. Heat Treat. 2011, 32, 12-17.

10. Wu, Z.W.; Meng, L. Influences of different prior heat treatments on the microstructural and mechanical properties of $\mathrm{Cu}-\mathrm{Fe}$ filamentary composites. J. Alloy. Compd. 2011, 509, 8917-8921. [CrossRef]

11. Liu, K.; Jiang, Z.; Zhao, J.; Zou, J.; Lu, L.; Lu, D. Thermal stability and properties of deformation-processed Cu-Fe in situ composites. Metall. Mater. Trans. A 2015, 46, 2255-2261. [CrossRef]

12. Zou, J.; Lu, D.P.; Liu, K.M.; Zhou, Z.; Fu, Q.F.; Zhai, Q.J. Effect of alternating magnetic field on the microstructure and solute distribution of $\mathrm{Cu}-14 \mathrm{Fe}$ composites. Mater. Trans. 2015, 56, 2058-2062. [CrossRef]

13. Zou, J.; Lu, D.-P.; Liu, K.-M.; Fu, Q.-F.; Zhou, Z. Influences of alternating magnetic fields on the growth behavior and distribution of the primary Fe phase in $\mathrm{Cu}-14 \mathrm{Fe}$ alloys during the solidification process. Metals 2018, 8, 571. [CrossRef]

14. Raabe, D.; Ohsaki, S.; Hono, K. Mechanical alloying and amorphization in $\mathrm{Cu}-\mathrm{Nb}-\mathrm{Ag}$ in situ composite wires studied by transmission electron microscopy and atom probe tomography. Acta Mater. 2009, 57, 5254-5263. [CrossRef]

15. Liu, K.; Lu, D.; Zhou, H.; Atrens, A.; Chen, Z.; Zou, J.; Zeng, S. Influence of Ag micro-alloying on the microstructure and properties of $\mathrm{Cu}-7 \mathrm{Cr}$ in situ composite. J. Alloy. Compd. 2010, 500, 27-32. [CrossRef]

16. Gao, H.; Wang, J.; Shu, D.; Sun, B. Effect of Ag on the microstructure and properties of Cu-Fe in situ composites. Scr. Mater. 2005, 53, 1105-1109. [CrossRef]

17. Wang, Y.F.; Gao, H.Y.; Wang, J.; Han, Y.F.; Dai, Y.B.; Sun, B.D. First-principles calculations of Ag addition on the diffusion mechanisms of $\mathrm{Cu}-\mathrm{Fe}$ alloys. Solid State Commun. 2014, 183, 60-63. [CrossRef]

18. Zou, J.; Zhai, Q.J.; Liu, F.Y.; Liu, K.M.; Lu, D.P. Influences on distribution of solute atoms in Cu-8Fe alloy solidification process under rotating magnetic field. Metals Mater. Int. 2018, 24, 1275-1284. [CrossRef]

19. Gao, H.; Wang, J.; Shu, D.; Sun, B. Effect of Ag on the aging characteristics of Cu-Fe in situ composites. Scr. Mater. 2006, 54, 1931-1935. [CrossRef]

(C) 2018 by the authors. Licensee MDPI, Basel, Switzerland. This article is an open access article distributed under the terms and conditions of the Creative Commons Attribution (CC BY) license (http://creativecommons.org/licenses/by/4.0/). 